\title{
Use (and misuse) of instrumental variables
}

\author{
Emilia Bagiella, $\mathrm{PhD}$
}

\footnotetext{
From the Department of Population Health Science and Policy, Icahn School of Medicine at Mount Sinai, New York, NY.

Disclosures: Author has nothing to disclose with regard to commercial support.

Received for publication July 14, 2015; accepted for publication July 14, 2015; available ahead of print Aug 4, 2015 .

Address for reprints: Emilia Bagiella, PhD, Department of Populations Health Science and Policy, Icahn School of Medicine at Mount Sinai, One Gustave L. Levy Place, Box 1077, New York, NY 10029 (E-mail: emilia. bagiella@mountsinai.org).

J Thorac Cardiovasc Surg 2015;150:460

$0022-5223 / \$ 36.00$

Copyright (c) 2015 by The American Association for Thoracic Surgery

http://dx.doi.org/10.1016/j.jtcvs.2015.07.047
}

In the recent article "Comparison of in-hospital and longerterm outcomes of hybrid and Norwood stage 1 palliation of hypoplastic left heart syndrome," Malik and colleagues ${ }^{1}$ tackle a very interesting and challenging methodological issue often encountered in the analysis of observational, nonrandomized studies.

The authors use a large administrative database to explore the efficacy of a hybrid procedure for the surgical treatment of hypoplastic left heart syndrome (HLHS) compared with the more traditional Norwood procedure. The analysis includes 3654 infants with HLHS, of whom 242 received the hybrid procedure. Of note, a number of hospitals did not perform the hybrid procedure.

To eliminate or decrease the bias brought about by the noncomparability of the 2 groups at baseline, the authors used hospital volume of hybrid procedures as an instrumental variable (IV). The methodology, developed in economics, has been in recent years effectively adapted for application to clinical data.

An IV is a variable that acts as a "randomizer" in data analysis. One crucial assumption for the correct use of IVs is that the IV is associated with the intervention of interest but not directly to the outcome. Note that this assumption cannot be tested empirically, and therefore the choice of the IV is often based on a judgment call.

The authors' choice of the IV is common in clinical applications, and it is based on the rationale that patients undergoing operation at high-volume hospitals have a higher change of receiving the hybrid procedure. If the volume of procedures does not change in response to the outcome of the procedure, then the choice of the hospital becomes a randomizer for the procedure.

In the reported study, however, given the infrequency of the procedure, it is likely that only those hospitals in which the procedure was successful (ie, resulted in improved outcome) increased or continued its use. Therefore, the volume of procedure becomes directly dependent on the outcome through a feedback mechanism, thus breaking a critical assumption. The resulting analysis could be

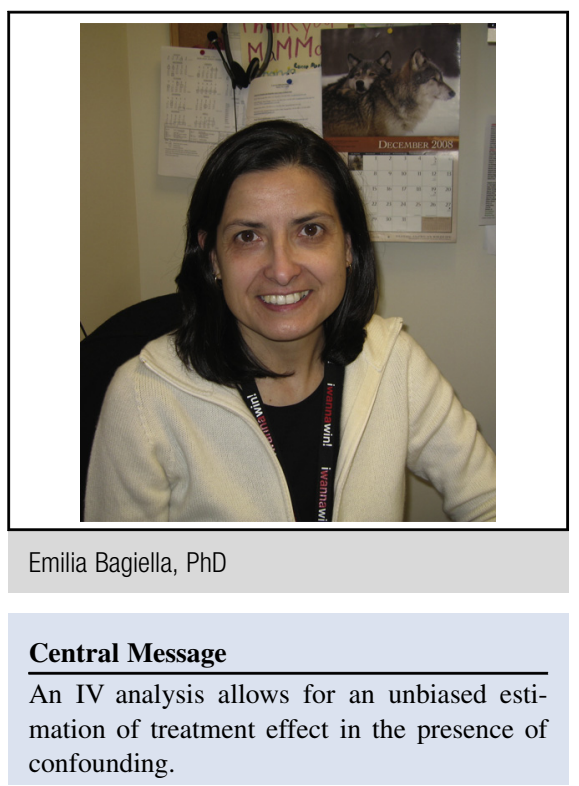

See Article page 474

severely biased toward the alternative hypothesis that the hybrid procedure improves outcome.

In a series of sensitivity analyses, the authors used a dichotomous (high vs low volume) IV, as well as the procedure used to treat the previous patient with HLHS at the same hospital as the IV. Both approaches would lessen the association between the IV and the outcome.

These sensitivity analyses showed that the effect was in the same positive direction; however, the effect sizes were attenuated, and for some, the outcomes were no longer significant. These more conservative analyses should have been presented as the primary analyses. The understandable desire to report statistically significant (albeit biased) results should be overcome with an obligation to report more conservative but less biased findings.

As the availability of data from electronic medical records, clinical registries, and administrative databases increases, adequate statistical methodology is necessary to ensure an unbiased inferential process and to lead to the correct conclusions and actions. The improper use of these techniques may introduce more biases and compromise the validity of the findings.

\section{Reference}

1. Malik S, Bird TM, Jaquiss RDB, Morrow R, Robbins JM. Comparison of in-hospital and longer-term outcomes of hybrid and Norwood stage 1 palliation of hypoplastic left heart syndrome. J Thorac Cardiovasc Surg. 2015;150: 474-80.e2. 